\title{
EFFECT OF PHASE COMPOSITION ON THE PARAMETERS OF NON-ISOTHERMAL MOISTURE TRANSFER IN UNSATURATED SANDY SOILS
}

\author{
Vladimir A. KOROLEV, Elena A. FEDYAEVA \\ Geological Faculty of Moscow State University named M. V. Lomonosov MSU, \\ 119991 Leninskie Gory, Moscow, Russia
}

Received 15 Mar 2013; accepted 13 Jun 2013

\begin{abstract}
This paper considers the influence of phase composition on the parameters of non-isothermal moisture transfer in unsaturated sandy soils. The technique of study options non-isothermal moisture transfer to disperse soil of disturbed structure. The exploratory procedure of the parameters in disperse soils having disturbed structure in the wide range of their phase composition using triangular diagrams is expounded. Shown that the parameters non-isothermal moisture transfer depend on moisture content and soil composition density. Established that for the sandy soil there is the "optimal" range of moisture content and density at which the non-isothermal moisture transfer is most efficient. The dynamics of the field moisture content of sand in time is identified.
\end{abstract}

Keywords: non-isothermal moisture transfer, thermo-osmosis, unsaturated sandy soil, phase composition, soil temperature gradient, triangular diagram of the phase composition, moisture content, soil composition density.

Reference to this paper should be made as follows: Korolev, V. A.; Fedyaeva, E. A. 2014. Effect of phase composition on the parameters of non-isothermal moisture transfer in unsaturated sandy soils, Journal of Civil Engineering and Management 20(1): 95-102. http://dx.doi.org/10.3846/13923730.2013.843584

\section{Introduction}

Non-isothermal moisture transfer - the process of moisture migration in soil under the influence of a temperature gradient, has been studied obviously insufficiently. Available separate works studying this phenomenon have been executed generally by soil scientists for different types of soils (Briling, Pashkowski 1982; Childs 1973; Korolev 1997). The most important basic researches of non-isothermal moisture transfer were executed by Globus (1983, 2009). Vertical non-isothermal moisture transfer in soil of aeration zone under the conditions of daily temperature fluctuations is rather well studied (Grifoll et al. 2005; Prasad et al. 2001; Raats et al. 2002). But the number of researches of non-isothermal moisture transfer in the quasi-closed systems of various natural soil, including sandy, is very limited (Cary, Taylor 1962a, b; Dempsey 1978; Hopmans, Dane 1986). At the same time, the urgency to study the problem of non-isothermal moisture transfer is dictated by the problems of moisture transfer forecasting in disperse soil under various thermodynamic conditions of the environment in connection with hydraulic engineering construction, heating systems construction, gas and oil pipelines, the nuclear power plant construction, combined heat and power plant and other thermal power constructions, and also by the solution of a number of theoretical tasks.

In disperse soil, not completely water saturated with water, moisture transfer is carried out under the influence of the corresponding gradients of transfer potentials caused by thermodynamic conditions of the system (Cassel et al. 1969; Globus 1983, 2009). So in the absence of a temperature gradient within the considered volume of not completely saturated soil system (isothermal conditions, $T=$ const grad $T=0$ ) moisture transfer occurs both in liquid, and in a steam phase under the influence of moisture potential (pressure) gradient.

At existence in soil volume of a temperature gradient (not isothermal conditions), under the influence of $\operatorname{grad} T \neq 0$ there are additional streams of steam, water and heat which "being imposed" on isothermal streams, make the general mass transfer more complicated. In this case the non-isothermal moisture transfer mechanism is complex; it can be caused by a water thermo-osmosis, thermo-diffusion, thermo-meniscus and thermo-capillary current of moisture, etc. (de Vries 1987; Korolev 1997; Korolev et al. 1990). Thus, to characterize the non-isothermal moisture transfer in soil, two parameters are gen-

Corresponding author: Vladimir A. Korolev

E-mail: va-korolev@bk.ru 
erally used: moisture transfer $D_{w}$ and thermo-transfer of $D_{T}$ factors which are connected by a ratio:

$$
V_{w m}=\frac{J_{w T}}{\rho_{w}}=-D_{w}\left(\frac{d W_{0}}{d x}\right)-D_{T}\left(\frac{d T}{d x}\right)
$$

where: $V_{w m}$ - linear speed of moisture transfer; $J_{w T}-\mathrm{a}$ total non-isothermal moisture stream; $\rho_{w}$ - water density; $W_{0}$ - volumetric moisture content; $T$ - temperature; $x$ - coordinate along a temperature gradient (moisture transfer).

The separate factors influencing parameters of non-isothermal moisture transfer in sandy and clay soil have been studied in a number of works (Korolev et al. 1990; Sophocleous 1979; Thomas, He 1995; Voronin 1984). However many factors still remain poorly studied. For example, the influence of soil phase composition and degree of pore filling with water on non-isothermal moisture transfer parameters is unknown. Earlier it was established that non-isothermal moisture transfer was possible only at a certain degree of soil humidity: soil water saturation over this range led to non-isothermal moisture transfer decrease and to its disappearance at almost complete water saturation; and on the other hand, decrease in degree of pore filling with water also led to non-isothermal moisture transfer reduction since the total volume of moisture in soil decreased. But, if the area of possible change of phase composition of this soil was quite considerable and depends not only on pore filling with water, but also on density (porosity) of soil shape, i.e. on a possible ratio of all three phases, the area in soil, where it was possible the non-isothermal moisture transfer, was not clear.

Therefore the purpose of this work is to study the influence of sand phase composition in a wide range of change of its ratios of solid, liquid and gas phases in the basic non-isothermal moisture transfer parameters moisture transfer $D_{w}$ coefficient and thermo-transfer $D_{T \text { coefficient }}$.

\section{Materials and methods}

\subsection{Objects}

Sand of alluvial genesis (aQIIIsb) from the Moscow-river valley was chosen as object of research. The main rock forming mineral in it is presented by quartz, any other impurity being absent. The structure of the studied sand granular, it belongs to medium sands of particle size distributions. Soil particle density $-2.67 \mathrm{~g} / \mathrm{cm}^{3}$, the maximum hygroscopic humidity $-0.3 \%$, humidity of a capillary moisture capacity $-13 \%$; humidity of a full moisture capacity - from $25 \%$ to $31 \%$ at dense and friable shape respectively; coefficient of permeability of soil $-5.76 \mathrm{~m} /$ days.

Sand samples of the broken shape were studied at different density and humidity (a different ratio of solid, liquid and gaseous phases) created artificially and at known initial condition.

\subsection{Technique of researches}

Investigation technique is observation of the dynamic changes in the initial moisture distribution along the length of an analysable sand sample under given temperature conditions, i.e. at the set temperature gradient. To carry out experiences the laboratory thermo-osmotic installation was used shown on Figure 1. It consisted of three plastic tubes $10 \mathrm{~cm}$ long (2) with analysable soil (1), which were densely closed from butt ends and were located between two metal plates (4 and 5), one of them being a heat exchanger or a heater (5). The tubes were located under the temperature control into heat-insulating shell (8). The whole thermo-osmotic installation was placed in a heat insulated housing that was made of foam plastic.

To receive the fullest picture of dependence of non-isothermal moisture transfer parameters from sand phase composition, the wide moisture range - from 3 to $20 \%$ was studied.

The technique of researches is the following. The studied sand was put in plastic tubes (Fig. 1) with a certain degree of compaction - the dry density of soil was created by steps (series of experiences) in a range from 1.11 to $1.69 \mathrm{~g} / \mathrm{cm}^{3}$. In each experience, the sand sample (1) previously humidified to a certain humidity, was loaded into three tubes (2) $10 \mathrm{~cm}$ long and internal diameter of $2 \mathrm{~cm}$ (three twin samples were formed). Butt ends of tubes were pressurized by rubber covers (3) (Fig. 1) to exclude moisture evaporation. Further tubes (2) were located in a foam plastic casing (8) which on the one end was closed with an aluminium plate (4), on the other end - with the hollow copper tank heat exchanger (5) through which hot water with the set temperature circulated. Thus the demanded constant temperature gradient ( $\sim$ the 2 nd hail $/ \mathrm{cm})$ was set in tubes. The size of a set temperature gradient was supervised with the help of the thermocouples (6) placed into one of the tubes (2). Water moves into the pores of the soil from the hot end to the cold under the action of the temperature gradient.

For the analysis of experiment data on non-isothermal moisture transfer in soil the Eqn (1) was used. During certain time $(4,7$ and 20 hours since the experience beginning) 5 tests on humidity ( 1 average, 2 at

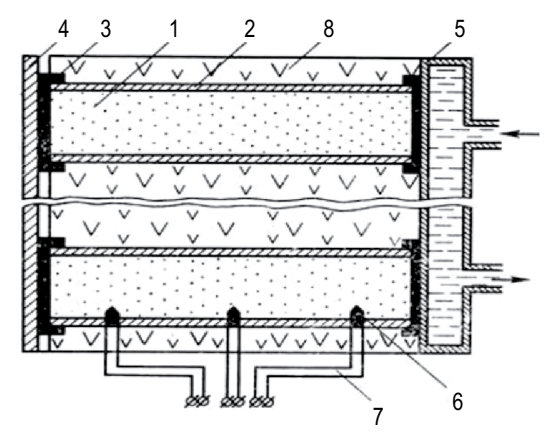

Fig. 1. The thermo-osmotic installation scheme for research of non-isothermal moisture transfer parameters: 1 - a soil sample; 2 - a tube; 3 - a cover; 4 - a plate; 5 - the heat exchanger; 6 - thermo-sensitive elements; 7 - conclusions of conductors; 8 - a heat-insulating shell 
butt ends and 2 intermediate) were selected along the length from every tube to make the analysis, and according to the received data moisture content profiles of $W=$ $f(x)$, where $x$ - coordinate along length of a sample were drawn. All experiments were performed repeatedly. It is possible to obtain reliable data.

According to the received profiles coefficients of $D_{w}$ and $D_{T}$ were calculated by a solution of the redefined system of the equations:

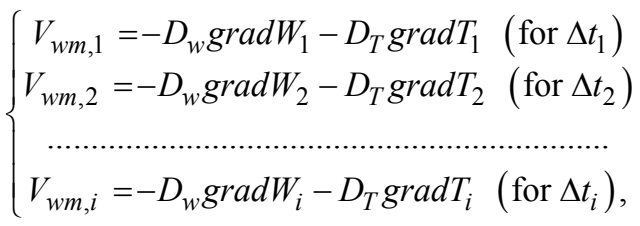

where the line above the parameters means averaging of sizes for this interval of time $\left(\Delta \mathrm{t}_{i}\right)$. The left part of the equations was calculated by graphic integration of experimental moisture content profiles:

$$
V_{w m}=\frac{\left[\left(\int_{0}^{x} W d x\right)_{t 2}-\left(\int_{0}^{x} W d x\right)_{t 1}\right]}{t_{2}-t_{1}},
$$

where $x$ - distance from a cold butt end of a tube $(x=0)$ to considered section. Humidity and temperature gradients were found by averaging of gradW and gradT at the time moments of $t_{1}$ and $t_{2}, t_{2}$ and $t_{3}$, etc. Calculation of non-isothermal moisture transfer integral characteristics was carried out on below-mentioned formulas (Trofimov et al. 2005).

The redistributed moisture share $\left(\Sigma_{w T}\right)$ of all water being in the system profile was calculated on the formula for a stationary:

$$
\Sigma_{w T}=\frac{W_{0} x_{\infty}-\int_{0}^{x_{0}} W d x}{W_{0} l_{m}},
$$

where: $x_{\infty}$ - profile $W$ coordinate, when $W x_{\infty}=W_{0} ; W_{0}-$ initial moisture; $l_{m}$ - coordinate of midship.

Humidity difference $(\Delta W)_{c h}$ between cold and hot borders of the system or "a humidity gradient" according to Smith was calculated as (Trofimov et al. 2005):

$$
(\Delta W)_{c h}=W_{c}-W_{h},
$$

where: $W_{c}$ - humidity at a "cold" butt end of a tube; $W_{h}-$ humidity at a "hot" butt end of a tube.

$A$ "humidity" thermal-gradient coefficient for a stationary profile of soil $\left(\delta_{w}\right)$ was defined by the equation:

$$
\delta_{w}(W, T)=\frac{D_{T}}{D_{w}}=-\left(\frac{d W}{d T}\right)_{t \rightarrow \infty} .
$$

\subsection{Computer program algorithm}

To accelerate and simplify the specified calculations the following computer program algorithm was made:

1. Data input: the number of moisture content profiles; values of humidity for each profile from a cold butt end to the tube middle; time formation of each profile $t_{i}$; values of humidity at cold and hot butt ends of a tube; values of temperature at cold and hot butt ends of a tube with the studied soil.

2. Calculations:

1) amounts of the redistributed moisture for each profile (the standard subprogram of calculation of a certain integral on a formula of parabolic trapezes (Simpson's method) is used);

2) linear speed of $V_{w m}$ of moisture transfer through individual section $x$ a column for the time interval of $t_{2}-t_{1}$ on an Eqn (3);

3 ) the maximum stream of $q_{w T}$ moisture on the average section $x$ columns during $t$ on an Eqn (7):

$$
q_{w T}=V_{w m} t
$$

4) shares of the moisture redistributed in a sample $\Sigma_{w T}$ on Eqn (4); gradients of humidity grad $W$ and temperature grad $T$ for each profile:

$$
\operatorname{grad} W=\frac{\Delta W}{\Delta x}, \operatorname{grad} T=\frac{\Delta T}{\Delta x} ;
$$

5) moisture transfer coefficient $D_{w}$ and thermal transfer coefficient $D_{T}$ were calculated with means of the subprogram of the decision of the redefined system of the equations (2) by square roots method; 6) A "humidity" thermal-gradient coefficient $\delta_{w}$ was calculated by the Eqn (6).

3. Printing of calculated results.

\subsection{Processing of the results}

As the result of the conducted experiments moisture content profiles $W=f(x)$, characterizing dynamics of humidity fields of samples in time, were received. In sand, as well as in other soil, moisture moves from the hot to the cold butt end of a column in the closed system conditions. Thus moisture is affected by two multidirectional motion forces: under the influence of $\operatorname{grad} T$ - vapour-liquid transfer and under the influence of grad $W$ - "isothermal" moisture transfer. At the initial stage of moisture transfer the first of them considerably exceeds the second. Therefore there is quite active transfer of moisture from the hot butt end to the cold one. But in the process of grad $W$ increase the second force increases and gradually slows down this process. When the action of forces is balanced, thermo-transfer of moisture comes to an end; the profile becomes stationary (Fig. 2). According to profiles $W=$ $f(x, t)$ integrated and "absolute" non-isothermal moisture transfer characteristics, mentioned above were received.

The chosen ranges of humidity and density of the studied sand allowed to study change dependences of the main non-isothermal moisture transfer characteristics on soil humidity in the range of $W_{m g}<W<W_{\text {cap }}$ (where $W_{m g}$ is maximum hygroscopic humidity, $W_{c a p}$ is capillary moisture-capacity humidity) and at various density degree of and soil humidity degree.

For the analysis of the received results the triangular diagram of the phase composition was used (Korolev 1997). This diagram reflects in a graphically a possible correlation of solid, liquid and gaseous soil phases at various density and humidity soil values (Fig. 3). 


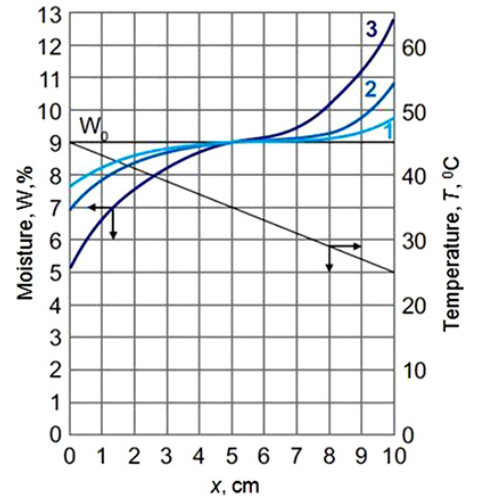

Fig. 2. A characteristic moisture content profile and the established distribution of temperature $T$ on length of a sample $x$ at initial humidity of $W_{0}=15 \%$. Time from the beginning of experience, h: $1-4 ; 2-7 ; 3-20$

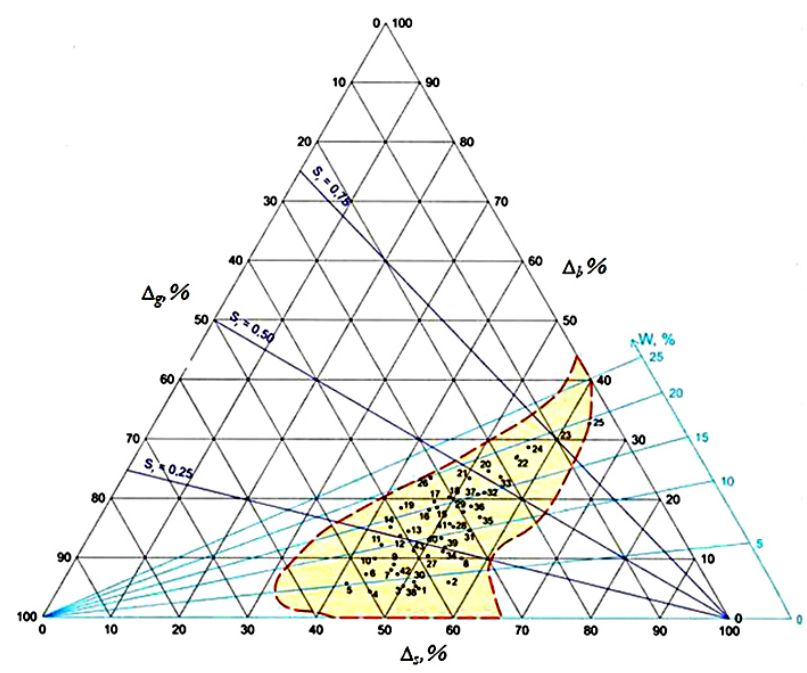

Fig. 3. Diagram of phase composition of sand with the numbers of control points: the dotted line is an area of possible correlation of phases in this soil; $W$ is gravimetric humidity; $S_{r}$ is a humidity degree

On this diagram each side of the triangle reflects the relative volume contents of one of three soil phases solid $\left(\Delta_{s}\right)$, liquid $\left(\Delta_{l}\right)$ and gaseous $\left(\Delta_{g}\right)$, each top corresponds to $100 \%$ of the content of one of them, and the point inside the diagram characterizes a certain ratio of volume portions of the considered three phases in this soil, the sum of each volume fraction is equal $100 \%$ (Korolev 1997).

The volume fraction of water on the diagram corresponds to volume soil humidity. On the same diagram the gravimetric water content $W$ (gravimetric moisture content in percent, the lines leaving the left bottom top) and humidity coefficient (degree) $S_{r}$ (the lines leaving the right bottom top) are reflected. Thus the lines parallel to one of the sides of Gibbs triangle correspond to systems with the identical content of one of the phases, and the straight lines drawn from the tops of the triangle before crossing with the opposite side, correspond to systems with an identical ratio of any two phases.
To draw the point on the diagram, it is necessary to know the correlation of some two of its phases, or two parameters characterizing a soil physical condition (for example porosity and volume humidity, or porosity and humidity degree, etc.). Further according to soil experiment data and the technique described in, the area of possible ratios of volume fractions of the studied sand phases was circled at its various shape and humidity (on Figure 3 this area is limited to a dashed line). Such triangular diagram is convenient as any soil parameter put on in isolines allows judging their variation at any possible ratio of this soil phases or its change (Korolev 1997).

For each experience corresponding to a certain ratio of phases at the beginning of the experiment, the numbered points were put on the diagram (Fig. 3). The coefficient values $D_{w}$ and $D_{T}$ calculated by the experiment results were appropriated. These points were connected to make isolines (Figs 4a, b). Similarly diagrams were made for other non-isothermal moisture transfer parameters.

\section{Results and discussion}

As a result of the specified constructions the authors received phase composition diagrams of analysed sand the values of various studied non-isothermal moisture transfer parameters put on them in the form of isolines (Figs 4-9).

So, on Figure 4 the diagrams of moisture-transfer coefficient $\left(D_{w} \cdot 10^{-3}, \mathrm{~cm}^{2} / \mathrm{s}\right)$ and thermo-transfer coefficient $\left(D_{T} \cdot 10^{-6}, \mathrm{~cm}^{2} / \mathrm{dg} \cdot \mathrm{s}\right)$ values depending on sand phase composition are presented. As a whole, their values location on the diagram has quite clear central symmetric character with the maximum values of non-isothermal moisture transfer parameters at $W=12.9 \%$ and $\rho_{d}=1.40 \mathrm{~g} / \mathrm{cm}^{3}$. These values decrease to the periphery of possible change area of sand phase composition (Fig. 4). Thus there is some correspondence of a $D_{w}$ and $D_{T}$ isolines form to a border form areas of volume fractions possible change of this soil phases (a dotted line on Figures 3 and 4).

The received results testify to strong $D_{w}$ and $D_{T}$ parameters dependence first of all of a sand phases ratio and of sand humidity, more precisely of certain moisture categories of different power types present in soil. So, the maximum values of $D_{w}$ and $D_{T}$ coefficients (equal $5.35 \cdot 10^{-3} \mathrm{~cm}^{2} / \mathrm{s}$ and $7.29 \cdot 10^{-6} \mathrm{~cm}^{2} / \mathrm{dg} \cdot \mathrm{s}$, accordingly) are marked at gravimetric moisture content, approximately corresponding to humidity of sand capillary moisture capacity. As suggested before, the main contribution to the moisture transfer process is brought by capillary water. Reduction of $D_{w}$ and $D_{T}$ coefficients at humidity being more than the most favourable one for this process, it is possible to explain that with the further increase of water amount in capillaries the free space volume for steam movement diminishes. And also the portion of through pores where steam can freely move goes down. At humidity being less than the most favourable one, there is a deficit of vaporous moisture apt at transferring into the sand pores, therefore the $D_{w}$ and $D_{T}$ coefficients decrease. 

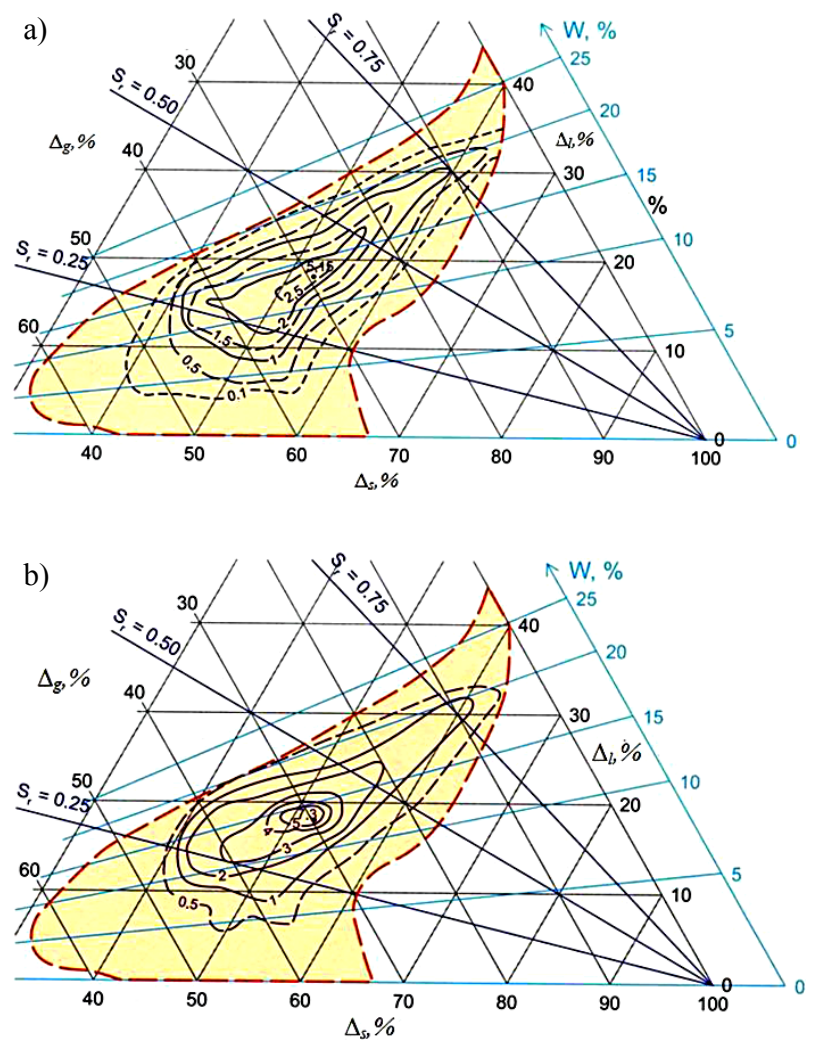

Fig. 4. Diagrams of moisture-transfer coefficient values $\left(D_{w}\right)$ and thermo-transfer coefficient values $\left(D_{\mathrm{T}}\right)$ depending on sand phase composition: $a-D_{w} \cdot 10^{-3}, \mathrm{~cm}^{2} / \mathrm{s} ; b-D_{T} \cdot 10^{-6}, \mathrm{~cm}^{2} / \mathrm{dg} \cdot \mathrm{s}$

However, from the presented diagrams it is visible that non-isothermal moisture transfer process influences not only humidity, but also soil structure - its density. $D_{w}$ and $D T$ coefficients are always less (at the same humidity) at the lowest soil density $\left(1.11-1.18 \mathrm{~g} / \mathrm{cm}^{3}\right)$, that is $D_{w, \text { fr }}<D_{w, \mathrm{c}}$ and $D_{T, \mathrm{fr}}<D_{T, \mathrm{c}}$, where the subscripts indicate the character of the soil density: "fr" - friable, "c" - compact. Further, as soil density increases these values increase, but, because of centrally-symmetric character of their location on the considered triangular diagrams when they reach some mean value of density (about $1.30-1.42 \mathrm{~g} / \mathrm{cm}^{3}$ making for investigated sand) they again begin to decrease, i.e. rows are observed rows: $D_{\mathrm{w}, \mathrm{fr}}<D_{\mathrm{w}, \text { aver }}>D_{\mathrm{w}, \mathrm{c}}$ and $D_{T, \mathrm{fr}}<D_{T, \text { aver }}>D_{T, \mathrm{c}}$ where the subscript "aver" means the average soil density (Fig. 4). It indicates that for every humidity value there is a certain density value at which the analysed moisture transfer parameters are the maximum.

The degree of pore filling with water $\left(S_{r}\right)$ also significantly influences $D_{w}$ and $D_{T}$ coefficients. On Figure 4 it is visible that non-isothermal moisture transfer is the most intensive at $S_{r}$ values from 0.25 to 0.5 . However at the same $S_{r}$ value $D_{w}$ and $D_{T}$ coefficients also change with soil density change. For example, at $S_{r}$ value equal to 0.378 the $D_{w}$ and $D_{T}$ values are $1.520 ; 5.346 ; 1.520$ $\left(\cdot 10^{-3} \mathrm{~cm}^{2} / \mathrm{s}\right)$ and $2.7 ; 7.3 ; 2.6\left(\cdot 10^{-6} \mathrm{~cm}^{2} / \mathrm{dg} \cdot \mathrm{s}\right)$ for density values $\rho_{d}$ equal to $1.27 ; 1.40 ; 1.47\left(\mathrm{~g} / \mathrm{cm}^{3}\right)$, accordingly. Thus, there is dependence $D_{w}$ and $D_{T}$ parameters with the density change (for identical values of the humidity degree), similar to such dependence for humidity change.

When the sand structure density decreases, the size of pores increases. But $D_{w}$ and $D_{T}$ coefficients increase only at the defined density values. For friable structure decrease of these coefficients is characteristic when density decreases. It is obviously due to the fact that this is change of the ratio of all the soil phases. The porosity increase at constant gravimetric moisture content reduces the percentage of moisture in comparison with a gas component. Hereupon at equal gravimetric moisture content (but with decreasing density) the same "deficiency" of moisture is observed, as well as with decreasing moisture while maintaining the same density. This results in corresponding decrease of $D_{w}$ and $D_{T}$ parameters.

Similar regularity is observed for other non-isothermal moisture transfer parameters too. So, on Figure 5 distribution of maximum moisture stream values $q_{w T}$ is shown by means of triangular diagrams 4 and 20 hours after the experience beginning, and on Figure 6 - the same for moisture redistribution speed $V 4$ hours after the experience beginning.

For both parameters the same central-symmetric character of these values location is observed. Moreover change dynamics of a sand humidity field within the time is traced: the maximum 4-hour and 20-hour values are equal: $q_{w T}-8.46$ and $3.05\left(\cdot 10^{-2}, \mathrm{~g} / \mathrm{cm}^{2}\right), V-5.87$ and $0.42\left(\cdot 10^{-6}, \mathrm{~cm} / \mathrm{s}\right)$, accordingly.
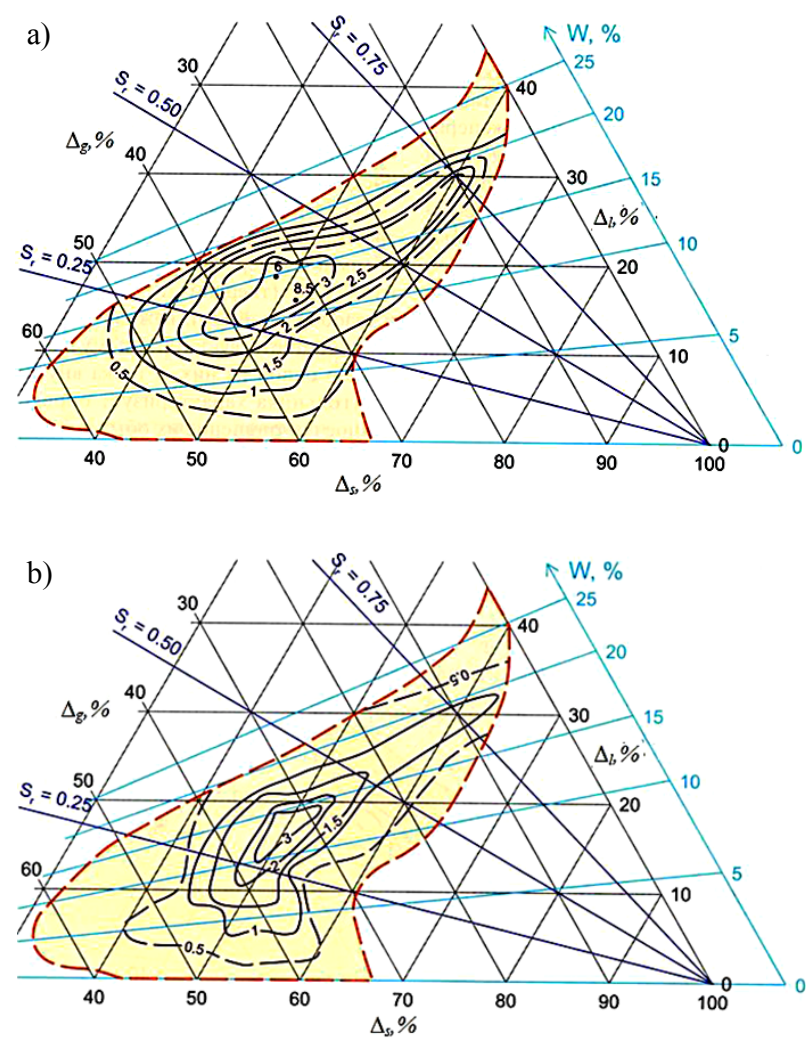

Fig. 5. The diagram of maximal moisture stream values of $q_{w T}-10^{-2}, \mathrm{~g} / \mathrm{cm}^{2}$ through 4 (a) and 20 (b) hours from the experience beginning depending on sand phase composition 


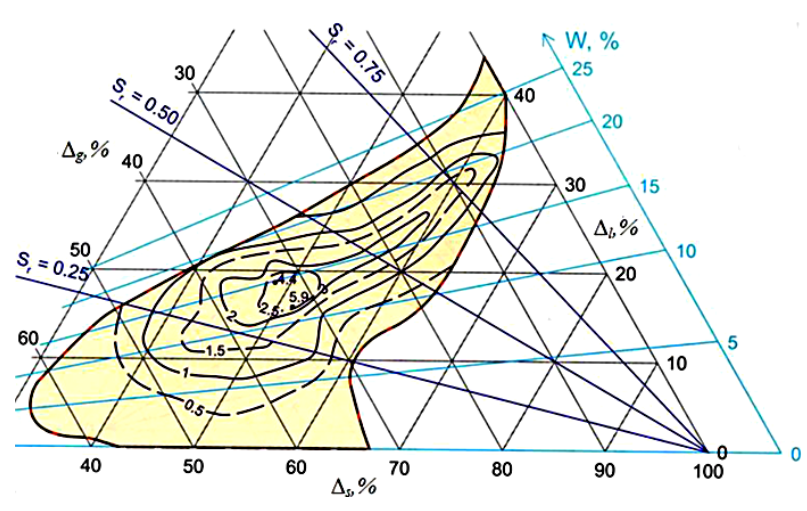

Fig. 6. The diagram of moisture redistribution speed values of $V \cdot 10^{-6}, \mathrm{~cm} / \mathrm{s}$ in 4 hours from the experience beginning depending on sand phase composition

It specifies that non-isothermal moisture transfer process actively proceeds during the first hours from the experience beginning, but within the time it is slowed down and stops when it reaches a stationary thermal field.

The sand structure density and its humidity degree considerably influence the range of moisture redistribution or humidity difference $(\Delta W)_{c h}$. In Figure 7, the value of the initial humidity (up to thermal moisture transfer) are shown by points, and the vectors of final humidity values formed in sand after 20 -hour thermal water transfer at the "cold" and "hot" butt ends of the sample are shown by arrows. It ensues from this triangular diagram that the maximum humidity difference is observed in the central part of the area of possible change of soil phase composition, i.e. it occurs at a certain correlation of all three soil phases.

It can be better seen in the diagrams with isolines of $(\Delta W)_{c h}$ (Fig. 8). An increase of this parameter is distinctly traced depending on time passing from the experience beginning $-4 \mathrm{~h} \mathrm{(a)}$ and $20 \mathrm{~h} \mathrm{(b)}$.

Thus if the area of maximum values of $(\Delta \mathrm{W})_{\mathrm{ch}}$ in case "a" corresponds to the gravimetric moisture con-

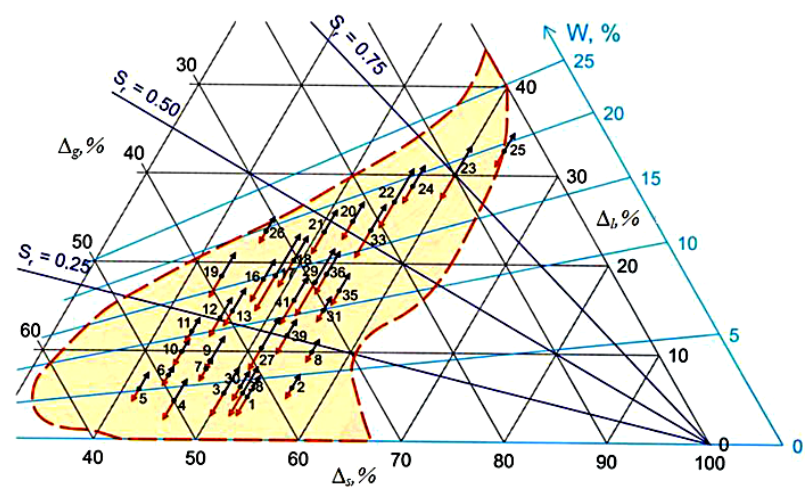

Fig. 7. Dynamics of sand gravimetric moisture content change at thermal moisture transfer after $20 \mathrm{~h}$ : points are the initial values of humidity before thermal moisture transfer, the figures near the points are numbers of experiments, the arrows are vectors of final moisture formed after thermal moisture transfer at "cold" (arrow pointing up) and "hot" (arrow pointing down) butt ends of the samples
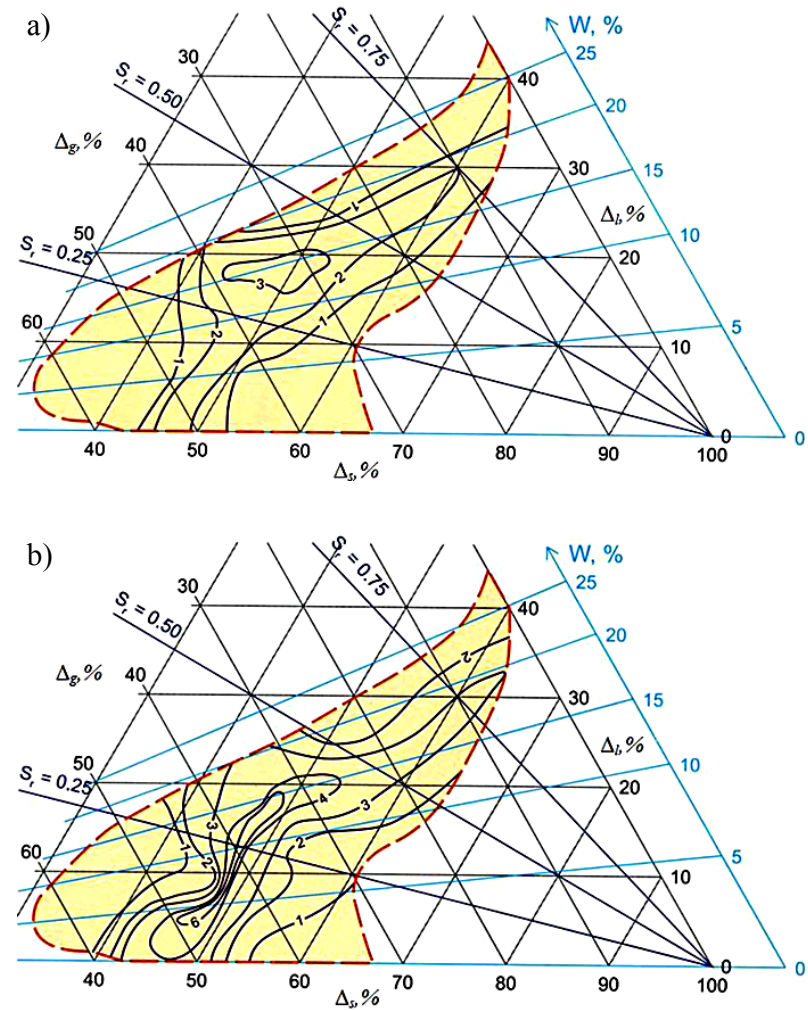

Fig. 8. Diagram of humidity gradient values $(\Delta \mathrm{W})_{c h}(\% / \mathrm{cm})$ : $a$-through $4 \mathrm{~h} ; b$-through $20 \mathrm{~h}$ after the experience beginning depending on sand phase composition

tent values $12.9-15.8 \%$ and to dry density of soil $1.16-$ $1.42 \mathrm{~g} / \mathrm{cm}^{3}$, then in case "b" this area is displaced toward lower humidity values $W$ and spreads in its wider range ( $W=3.5-13.8 \%)$. The interval of dry density of

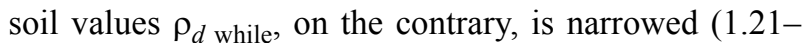
$\left.1.40 \mathrm{~g} / \mathrm{cm}^{3}\right)$. The minimum values $(\Delta \mathrm{W})_{c h}$ are observed at the most friable and most dense structure, and also at the greatest sand gravimetric moisture content values $(>20 \%)$.

The analysis of value distributions and development of a redistributed moisture portion within allows to establish (Fig. 9) that after the first 4 hours of thermal moisture transfer from the experience beginning (a) distribution of values of $\Sigma_{W T}$ as a whole is similar to that for earlier described parameters.

Within the time the maximum values of $\Sigma_{\mathrm{WT}}$ are strongly displaced on the diagram down, into the area of low humidity values: the greatest value of $\Sigma_{\mathrm{WT}}$, making $14.8 \%$, corresponds to humidity $W$ equal to $3.5 \%$ and dry density of soil $\rho_{d}$, equal $1.21 \mathrm{~g} / \mathrm{cm}^{3}$ that it is possible to explain features of the thermal moisture transfer mechanism.

Faintly moist soil contains much more amount of the pores, not filled with water able to absorb moisture migrating under the influence of grad $T$ (including in the form of vapour) than soil with high humidity. Therefore, the water in such soil completely transfers to the area with low temperature. 

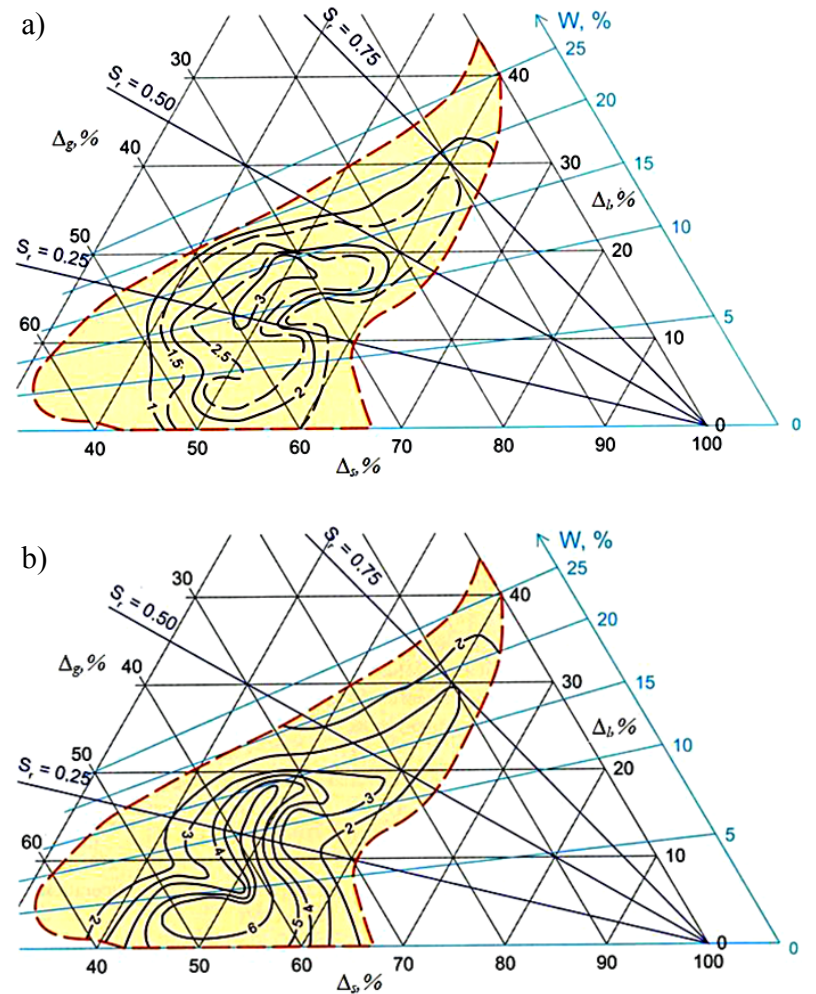

Fig. 9. Diagram of redistributed moisture share values $\Sigma_{\mathrm{WT}}(\%)$ : $a$-through $4 \mathrm{~h} ; b$-through $20 \mathrm{~h}$ after the experience beginning depending on sand phase composition

\section{Conclusions}

1. The technique for the analysis of various thermal moisture transfer parameters in soil by means of triangular diagrams of the phase composition is developed.

2. The areas of potential changes of soil thermal moisture transfer parameter values $\left(D_{w}\right.$ and $\left.D_{T}\right)$, expressed in the isolines, are established. Using the received diagrams it is possible to predict the thermal moisture transfer in the soil under any phase composition.

3. It is revealed that for the studied sandy soil there is the "most favourable" range of humidity and density values at which non-isothermal moisture transfer is the most effective. In our case it is humidity range of $11.7-13.8 \%$, and dry density of soil range of $1.30-1.42 \mathrm{~g} / \mathrm{cm}^{3}$. Outside this area (toward the periphery) values of soil thermal moisture transfer parameters $D_{W}$ and $D T$ decrease.

4. The value of $D_{w}$ and $D_{T}$ coefficients decrease in the area with low dry density of soil values when density decrease. It is due to the redistribution of all three soil phases ratio and causes moisture deficit (as well as at humidity reduction).

5. It is found that as a whole distribution of soil thermal moisture transfer parameters values has central symmetric character with the "most favourable" range of the studied soil humidity and density values (similarly noted in item 3 ).

6. It is established that at flowing of thermal water transfer process within the time not only there is an in- crease in values of a humidity gradient $(\Delta \mathrm{W})_{c h}$ and a redistributed moisture portion $\Sigma_{W T}$, but also outlines and positions change on the diagram of areas of their maximum values (there is a displacement in area of low humidity).

7. The results of these studies can be used to simulate moisture transport in soils under non-isothermal conditions

\section{References}

Briling, I. A.; Pashkowski, I. S. 1982. Defining the water transfer in connection with the forecast of soil water regime, Change the Geological Environment Due to Human Activity 81-89 (in Russian).

Cary, J. W.; Taylor, S. A. 1962a. The interaction of simultaneous diffusion of heat and water vapor in soil, Soil Science Society of America Journal 26(5): 413-416.

http://dx.doi.org/10.2136/sssaj1962.03615995002600050004x

Cary, J. W.; Taylor, S. A. 1962b. Thermally driven liquid and vapor phase transfer of water and energy in soil, Soil Science Society of America Journal 26(5): 417-420.

http://dx.doi.org/10.2136/sssaj1962.03615995002600050005x

Cassel, D. K.; Nielsen, D. R.; Biggar, J. W. 1969. Soil-water movement in response to imposed temperature gradients, Soil Science Society of America Journal 33(4): 493-500.

http://dx.doi.org/10.2136/sssaj1969.03615995003300040007x

Childs, E. 1973. Physical basis of soil hydrology. Leningrad: Gidrometeoizdat. 427 p. (in Russian).

de Vries, D. A. 1987. The theory of heat and moisture transfer in porous media revisited, International Journal of Heat and Mass Transfer 30(7): 1343-1350. http://dx.doi.org/10.1016/0017-9310(87)90166-9

Dempsey, B. J. 1978. A mathematical model for predicting coupled heat and moisture movement in unsaturated soil, International Journal for Numerical and Analytical Methods in Geomechanics 2(1): 19-34. http://dx.doi.org/10.1002/nag.1610020103

Globus, A. M. 1983. Physics nonisothermal subsurface water exchange. Leningrad: Gidrometeoizdat Press. 427 p. (in Russian).

Globus, A. M. 2009. Nonisothermal nature of soil profiles and soil hydrophysics, Eurasian Soil Science 42(2): 147-152. http://dx.doi.org/10.1134/S1064229309020057

Grifoll, J.; Gasto, J. M.; Cohen, Y. 2005. Non-isothermal soil water transport and evaporation, Advances in Water Resources 28(11): 1254-1266. http://dx.doi.org/10.1016/j.advwatres.2005.04.008

Hopmans, J. W.; Dane, J. H. 1986. Temperature dependence of soil hydraulic properties, Soil Science Society of America Journal 50(1): 4-9.

http://dx.doi.org/10.2136/sssaj1986.03615995005000010001x

Korolev, V. A. 1997. Thermodynamics of soils. Moscow: Moscow State University Press. 167 p. (in Russian).

Korolev, V. A.; Fedyaeva, E. A.; Akhromeeva, T. Y. 1990. Regularities of thermal moisture transfer in unsaturated disperse soils, Engineering Geology 3: 16-29 (in Russian).

Prasad, H. K. S.; Kumar, M. M. S.; Sekhar, M. 2001. Modelling flow through unsaturated zones: sensitivity to unsaturated soil properties, Sadhana 26(6): 517-528. http://dx.doi.org/10.1007/BF02703457

Raats, P. A. C.; Smiles, D. E.; Warrick, A. (Eds). 2002. Heat and mass transfer in the natural environment - a tribute to J. R. Philip, in Geophysical monograph series. Vol. 129. Environmental mechanics: water, mass and energy transfer in the biosphere. Washington: American Geophysical Society, 199-212. http://dx.doi.org/10.1029/GM129 
Sophocleous, M. 1979. Analysis of water and heat flow in unsaturated-saturated porous media, Water Resources Research 15(5): 1195-1206. http://dx.doi.org/10.1029/WR015i005p01195

Thomas, H. R.; He, Y. 1995. Analysis of coupled heat, moisture, and air transfer in a deformable unsaturated soil, Geotechnique 45(4): 677-689.

http://dx.doi.org/10.1680/geot.1995.45.4.677
Trofimov, V. T.; Korolev, V. A.; Voznesensky, E. A., et al. 2005. Soil knowledge. Trofimov, V. T. (Ed.). Moscow: Moscow State University Press. 1024 p. (in Russian).

Voronin, A. D. 1984. Structural-functional hydrophysics of soils. Moscow: Moscow State University Press. 204 p. (in Russian).

Vladimir A. KOROLEV. Graduate of Moscow State University (MSU), Faculty of Geology (1973), geological engineer and hydrogeologist, PhD (1978), Doctor of Geological and Mineralogical Sciences (1990), Professor of Geological Faculty of MSU, Department of Engineering and Environmental Geology (1993), Corresponding member of the Academy of Natural Sciences (1998), author of over 490 publications, including 25 textbooks and monographs. His research interests include various subjects of civil engineering, engineering and environmental geology, soil science, soil mechanics, soil thermodynamics, electrokinetic processes in soils, monitoring of the geological environment and remediation of contaminated sites, etc.

Elena A. FEDYAEVA. Graduate of MSU, Faculty of Geology (1990), geological engineer and hydrogeologist (1990-1991), geologist of Federal Geological Survey (1992-2007), engineer of Geological Faculty of MSU (2007), competitor of the Department of Engineering and Environmental Geology of MSU (2010), author of over 10 publications. Her research interests include soil science, civil engineering, water transfer in soils, etc. 